\title{
A RETROSPECTIVE STUDY OF CHILD DEATHS AMONG CASES REFERRED TO THE EGYPTIAN FORENSIC MEDICINE AUTHORITY DURING THE PERIOD FROM JANUARY TO DECEMBER 2016
}

Islam Mostafa Farrag a, Reham Nafad Elbendary ${ }^{\mathrm{b}}$, Hesham Abd El-Hamid Farag ${ }^{\mathrm{c}}$, Amani Abdel Fattah Bayoumi $^{\mathrm{b}}$

${ }^{a}$ Department of Forensic Medicine and Clinical Toxicology, Faculty of Medicine for girls, Al Azhar University, ${ }^{b}$ Department of Forensic Medicine and Clinical Toxicology, Faculty of medicine, Cairo university,

${ }^{c}$ Egyptian Forensic Medicine authority

\section{Corresponding author: Reham Nafad Elbendary}

Department of Forensic Medicine\& Clinical Toxicology, Faculty of Medicine, Cairo University, Egypt E-mail address: dr.rehamnafad@hotmail.com

\begin{abstract}
Background and objective: Child mortality rate is an important health index affected by many socioeconomic factors and reflects countries development and status. Autopsy in cases of children death is beneficial for Forensic medicine and medical research purposes. Children autopsy is conducted in the case of unnatural children deaths especially in the age group under 19 years of age. Similar to adults, trauma is the major cause of death in children, however it is important to identify other causes and age distribution of deaths. A study done in Pakistan showed that road traffic accident, poisoning and drowning accounted for $67 \%$ and $18 \%$ of children deaths respectively. The aim of this study was to describe frequency and pattern of unnatural deaths during childhood and adolescence in Great Cairo during a period of one year. Materials and methods : In one year period ( from 1 January 2016 till 30 December 2016 ), all medicolegal childhood deaths aged 0-20 years were investigated under the auspices of Forensic Medicine authority, and were retrospectively reviewed $(n=182)$. This number of cases represents $11.7 \%$ of the 1562 forensic autopsies performed during one year. Age, gender, cause and manner of death, autopsy findings, type of abuse and laboratory investigations were analyzed. Results: From this study we concluded that the total number of child deaths during one year period in the Great Cairo was around 182 cases. More than $50 \%$ of cases were males in the 2 nd decade, the perpetrator was not related to the victim in more than $70 \%$ of incidents, $70 \%$ of cases showed physical abuse. Male children deaths were mainly of homicidal or accidental nature, while females were of suicidal nature. Weapons related deaths in males were mainly blunt, sharp or firearm, while in females it was either poison or burn. $50 \%$ of cases with +ve toxicologic lab findings showed elevated Co levels followed by drugs of abuse. Conclusion: Urgent attention is required to be taken towards the problem of injury and violence against children and adolescents occurring through the world.
\end{abstract}

Key words: child deaths, child abuse, manner of death, cause of death, autopsy. 


\section{INTRODUCTION}

Maltreatment to children has existed as long as humanity has existed. The way children are treated has always been a faithful mirror reflection of the level of progress in the civility of humanity. Deaths from childhood injury are a public health problem worldwide. The death of a child is an important event in a community, and a defining marker of a society's policies of safety and health (Jenny and Isaak, 2006)

The death of any child is a heartbreaking tragedy for his family, and surrounding community. Most child fatalities result from natural or accidental causes. In cases of unexpected child deaths, law enforcement investigators are called to investigate any criminal activity involved in such deaths (Walsh, 2017).

Child fatalities related to maltreatment, abuse, and negligence occur worldwide. The detection and prevention of such crimes are the basic tenets underlying all child protective services (ACPO, 2014).

Child death as a result of abuse and neglect is a tragic outcome that occurs in all nations of the world. The true incidence of fatal child abuse and neglect is unknown. The most accurate incidence data of such deaths have been obtained from countries where multi-agency death review teams analyze the causes of child fatalities, as is done in the United States and Australia (Jenny and Isaak, 2006)

The Worldwide Health Organization (WHO) estimates that 57,000 children die annually as a result of maltreatment. Developing countries have higher rate of death than developed countries. Africa had the highest percentage of children deaths under the age of 5 due to homicidal causes. The rate was higher for boys than girls (World Health Organization, 2006).

Child homicides, although relatively rare, represent a social and medico-legal problem which attracts public attention worldwide; such cases are also among the most difficult and challenging for forensic pathologists ( Cordner et al., 2001). The incidence and other causes of these homicides may be closely related to social and economic changes within a particular society. Child maltreatment is a complex problem that stems from a variety of factors, including stress, poverty, substance abuse, and mental illness (Kajese et al., 2007)

Fatal child abuse is defined as the death of a child resulting from acts of physical violence or neglect of a child, perpetrated by a family member, caregiver or unknown perpetrators. Many researchers and practitioners believe that child deaths due to violence and neglect are still under reported. Although, it is well recognized through the medical literature, the true prevalence of child homicidal deaths is very difficult to assess (Brookman and Nolan, 2006)

Physical child violence was defined as physical aggression directed at a child by an adult, and child neglect was defined as the situation where the responsible adult fails to adequately provide for various needs, including physical (failure to provide adequate food, clothing, or hygiene), emotional (failure to provide nurturing or affection), or educational (failure to enroll a child in school) (Leeb et al., 2010)

The World Health Organization has defined child sexual abuse as: "The involvement of a child in sexual activity 
that he or she does not fully comprehend, is unable to give informed consent to, or for which the child is not developmentally prepared, or that violates the laws or social taboos of society (World Health Organization, 2003).

In Egypt, a death certificate is the official record of death. Death certificates include a determination of the cause and manner of death and are often used to summarize the deaths resulting from diseases and injuries. It is, however, well documented that these vital records underestimate the prevalance of fatal child maltreatment. In Egypt there are no true data about the incidence of fatal child deaths from violence and neglect, and there are difficulties in classifying deaths from maltreatment and the reality that such deaths are not always apparent, and do not fit into any particular pattern ( Moustafa and El Elimi , 2013). So, the aim of this research was to describe the frequency and pattern of unnatural deaths during childhood and adolescence in Great Cairo during a period of one year.

\section{MATERIALS AND METHODS}

A retrospective descriptive study to analyze and describe the frequency and pattern of deaths during childhood in Great Cairo during a period of one year. Data were collected through the period of one year (from 1 January 2016 till 31 December 2016), all medico-legal childhood deaths aged $0-18$ years were included in our study under the auspices of the Egyptian Forensic Medicine authority (EFMA) after obtaining ethical Approval and were retrospectively reviewed $(\mathrm{n}=182)$ representing $11.7 \%$ of the total of 1562 forensic autopsies performed during one year.

- Data collection sheet included the following items:

1- Socio demographics of child deaths:

- Residence.

- Age.

- Gender

- Season.

2-Characteristics of child deaths

- Who reported the incident.

- The caregiver responsible for the child.

- The assailant-child relationship.

- Type of abuse:

Physical abuse

$>$ Combined physical and sexual abuse,

No abuse (the incident was either accidental, self-inflicted or undetermined)

- Type of crime.

- Manner of death.

\section{External examination of child} deaths:

State of clothes among the studied cases.

$>$ External body findings.

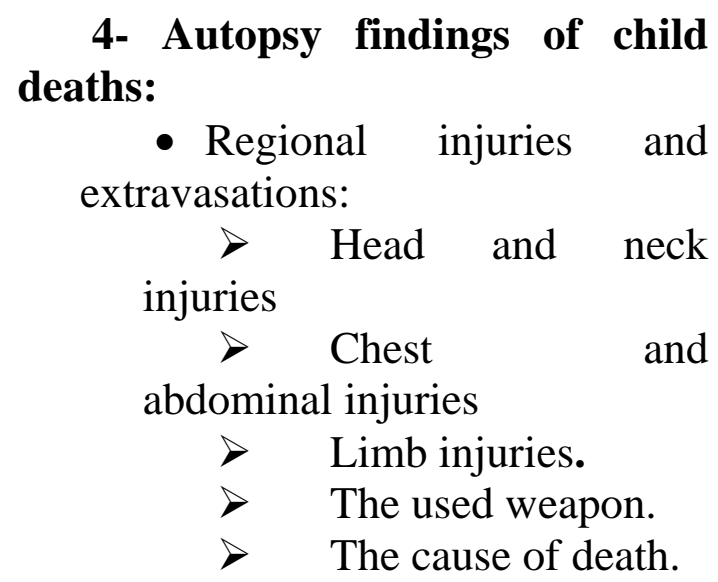


deaths.

\section{Laboratory findings of child}

\section{Data analysis:}

Data were coded and entered using the statistical package SPSS (Statistical Package for the Social Science; SPSS Inc., Chicago, IL, USA) version 22. Data was summarized using frequency (count) and relative frequency (percentage) for categorical data. Comparisons between categorical data, Chi square (c2) test was performed. Exact test was used instead when the expected frequency is less than 5 (Chan, 2003). P-values less than 0.05 were considered as statistically significant.

\section{RESULTS}

1- Socio demographics of child deaths

Total numbers of 1562 medico-legal autopsies (including all age groups of both genders) were done during January to December 2016 period, Out of which 182 cases $(11.7 \%)$ were children. The percent of distribution of cases was 103 cases (56.6\%) in Cairo, and 79 cases (43.4\%) in Giza and Qalyubia. Child deaths during summer were 67 cases (36.8\%) followed by Winter 46 cases (25.3\%) then, 37 cases (20.3\%) during fall and 32 cases (17.6\%) during spring.

Most cases were males $112(61.5 \%)$ as compared to females 70 (38.5\%) and were mostly in the second decade 94 cases $(51.6 \%)$, followed by first decade children 51 cases $(28 \%)$ and the least affected age group was infant 37 cases (20.4\%) [Table 1].

2-Characteristics of child deaths

2.1. who reported the incident, the caregiver responsible for the child and the assailant-child relationship:
86 cases $(47.3 \%)$ were reported by passing people, while 78 cases $(42.9 \%)$ by parents and only 18 cases (9.9\%) by hospital. One of the parents was the caregiver at the time of the incident in 109 cases $(59.9 \%)$ and the caregiver was undetermined in 56 cases $(30.8 \%)$ and other relatives were the caregiver in 17 cases $(9.3 \%)$. In majority of cases, the assailant was either a stranger or a relative other than the parents 133 cases (73.1\%), fathers were the assailant in 15 cases $(8.2 \%)$ while mothers were in 10 cases $(5.5 \%)$. In 12 cases $(6.6 \%)$, a physician was claimed to be the assailant and in 12 cases, the incident was selfinflicted [Table 2, fig. 1].

\subsection{Type of abuse}

131 cases $(72 \%)$ were subjected to physical abuse as compared to 5 cases (2.7\%) who were subjected to combined physical and sexual abuse, while 46 cases (25.3\%) showed no abuse (the incident was either accidental, self-inflicted or undetermined) [Table 2, fig. 2].

\subsection{Type of crime}

As regard different types of crimes related to child deaths and their relation to different age groups. No crime (accidental, malpractice claim, parental abuse or assailant with history of psychic illness), is the most common in 92 cases (50.5\%), of which 50 cases $(53.2 \%)$ were in the second decade, 23 cases $(45.1 \%)$ in the first decade and 19 cases (51.4\%) infants. Fighting or roberry was the second common type of crime representing 44 cases $(24.2 \%)$ of which 30 cases $(31.9 \%)$ were in second decade, 9 cases $(17.6 \%)$ in first decade and 5 cases $(13.5 \%)$ were infants. In 20 cases $(11 \%)$ the type of crime was undetermined. Malpractice was claimed 
in 12 cases (6.6\%) divided equally (6 infants and 6 in first decade). Crimes of honor/illegal child were reported in 8 cases $(4.4 \%)$ of which 3 cases $(3.2 \%)$ were in the second decade, 2 cases $(3.9 \%)$ in the first decade and 3 cases $(8.1 \%)$ infants. Sexual assault was the crime in only 6 cases $(3.3 \%)$ of which 5 cases $(5.3 \%)$ were in the second decade, 1 case $(2 \%)$ in the first decade[Table 3].

\subsection{Manner of death}

As for the manner of death, 62 cases (34.1\%) were homicidal, of which 47 cases $(42 \%, \mathbf{p}<\mathbf{0 . 0 0 1})$ were males and 15 cases $(21.4 \%)$ were females. 52 cases (28.6\%) were accidental, of which 33 cases (29.55) were males while 19 cases (27.1\%) were females. 27 cases $(14.8 \%)$ were either difficult labor, prematurity or malpractice claim, of which 16 cases $(14.3 \%)$ were males and 11 cases (15.7\%) were females. 26 cases $(14.3 \%)$ were suicidal, of which 7 cases $(6.2 \%)$ were males and 19 cases $(27.1 \%)$ were females. and only 15 cases $(8.2 \%)$ were pathological, of which 9 cases $(8 \%)$ were males and 6 cases $(8.6 \%)$ were females [Table 4, fig. 3].

3- External examination of child deaths

\subsection{Clothes}

Concerning clothes of the studied cases, the report of 7 cases $(3.8 \%)$ didn't mention the state of clothes, while 85 cases $(46.7 \%)$ showed no abnormality, 27 cases $(14.8 \%)$ were presented with either tear, burn or blood and 43 cases (23.6\%) were naked. While, 8 and 12 cases $(4.4 \%$ and $6.6 \%)$ were wearing wet clothes or hospital gown respectively [Table 5].

3.2. External body findings
External examination of the studied cases reveled no findings in 48 cases (26.4\%). Blunt injury (abrasion, contusion, contused wound) was the commonest type observed in 74 cases (40.7\%), followed by phyical injury in 23 cases $(12.6 \%)$ then penetrating injury in 22 cases $(12.1 \%)$. While decomposition was reported in 11 cases $(6 \%)$. Both old scars and external bleeding were obsrved in 2 cases $(1.1 \%)$ for each [Table 5].

4- Autopsy findings of child deaths

4.1. Regional injuries

Analyzing the site of trauma has showed that, multiple trauma regions were the commonest form present in this study 80 cases $(44 \%)$ including 3 cases with injury to genitalia. Head was the region where maximum number of injuries were observed, 29 cases (16\%) followed by the chest 21 cases $(11.5 \%)$, while neck, abdomen and lower limb injuries presented 9 cases $(5 \%), 7$ cases (4\%) and 6 cases $(3.3 \%)$ respectively. 30 cases $(16.2 \%)$ revealed negative autopsy findings. Extravasations was observed in 103 cases $(56.6 \%)$ [Table 6, fig. 4].

\subsection{Head and neck injuries}

On evaluating cases with head injuries; cerebral contusion or laceration was the commonest, representing 60 cases $(33 \%)$, followed by skull fractures 28 cases (15.4\%), then subdural, extradural, subarachnoid and combined meningeal hemorrhage in 14, 12, 10 and 5 cases $(7.7 \%, 6.6 \%, 5.5 \%$ and $2.7 \%$ ) respectively. While, neck injuries were in the form of hyoid fracture; 15 cases $(8.2 \%)$ and vascular injury in 10 cases (5.5\%) [Table 7, fig. 5]. On examining cases with head and neck injuries in relation to the age group, subarachnoid hemorrhage showed statistically significant higher $\%$ in infants as 
compared to other age groups. While, hyoid fracture showed statistically significant higher $\%$ in second decade victims as compared to other age groups [Table 8].

4.3. Chest and abdominal injuries

On considering cases with chest injuries; lung or heart laceration was the commonest, representing 62 cases $(34.1 \%)$, followed by hemo/pneumo thorax 42 cases $(23.1 \%)$, then fracture ribs and soot in airway in 18 and 3 cases (9.9\% and $1.6 \%)$ respectively. While, abdominal injuries were in the form of visceral laceration; 36 cases $(19.8 \%)$ and hemoperitoneum in 24 cases (13.2\%). On analyzing cases with chest and abdominal injuries in relation to the age group, rib fractures, lung/heart laceration/ congestion as well as hemoperitoneum showed statistically significant higher $\%$ in second decade victims as compared to other age groups [Table 7,8].

\subsection{Limb injuries}

On evaluating cases with limb injuries; lower limb injuries were more common than upper limb. Among upper limb injuries, bone fracture and muscular injury were seen in 6 cases for each (3.3\%) while, vascular injury was present in one case $(0.5 \%)$. As regard lower limb injuries, Fracture bones were the commonest injury, representing 11 cases (6\%), followed by muscular injury 7 cases $(3.8 \%)$, and the least was vascular injury in 6 cases (3.3\%) [Table 9].

4.5. Underlying cause of death

Concerning the underlying cause of death; trauma was the commonest cause of death (38.4\%), followed by malpractice claims or pathological in 52 cases $(28.6 \%)$. Asphyxia was the third cause in 30 cases $(16.5 \%)$ followed by thermal agent in 23 cases (12.6\%) and the least cause was poison in 7 cases (3.8\%)[Table 10, fig. 6].

Blunt trauma was the commonest cause of death (37 cases, 20.3\%), followed by penetrating (18 cases, $9.9 \%$ ) and the least was firearm injury (15 cases, $8.2 \%$ ) [Table 10].

On analyzing the relation between the underlying cause of death and gender, males showed statistically significant higher incidence than females with trauma, asphyxia and thermal injury, representing 50, 21, 12 (18.8\%, 44.7\%, $10.7 \%$ ) respectively. While, females showed statistically significant higher incidence than males in death with poison (5 cases, $7.1 \%$ ) [Table 10, fig. 7].

4.6. The direct cause of death

As regard the direct cause of death, 66 and 65 cases $(36.3 \%$ and $35.7 \%)$ died due to respiratory and cardiovascular failure respectively, while 31 cases (17\%) due to central nervous system failure. The cause of death in 20 cases $(11 \%)$ was either not documented or unknown [Table 11].

5- Laboratory findings of child deaths

As for the laboratory findings, 40 cases $(28 \%)$ their laboratory results were not available, 108 cases (59\%) were negative for toxicologic screening. 24 cases $(13 \%)$ were positive, $50 \%$ of these cases were positive for carbon monoxide, $16.7 \%$ and $4.2 \%$ were positive for tramadol and hashish respectively and only $4.2 \%$ were positive for organophosphate. 4 out of 5 cases with combined physical and sexual abuse were positive for semen [Table 12, Fig. 8]. 
Table 1: Distribution of child deaths according to season, age group, gender and residence $(n=182)$.

\begin{tabular}{|c|c|c|c|c|c|c|c|c|c|c|c|}
\hline Season & $n$ & $\%$ & Age group & $n$ & $\%$ & Gender & $n$ & $\%$ & Residency & $n$ & $\%$ \\
\hline Summer & 67 & 36.8 & ${ }^{\mathrm{a}}$ Infant & 37 & 20.4 & Male & 112 & 61.5 & Cairo & 103 & 56.6 \\
\hline Fall & 37 & 20.3 & $\begin{array}{l}\mathrm{b} 1 \mathrm{st} \\
\text { decade }\end{array}$ & 51 & 28 & Female & 70 & 38.5 & $\begin{array}{l}{ }^{\mathrm{c}} \text { Outside } \\
\text { Cairo }\end{array}$ & 79 & 43.4 \\
\hline Winter & 46 & 25.3 & 2nd decade & 94 & 51.6 & & & & & & \\
\hline Spring & 32 & 17.6 & & & & & & & & & \\
\hline
\end{tabular}

$n=$ number of cases, ${ }^{\mathrm{a}}: 0-2 \mathrm{y},{ }^{\mathrm{b}}: 2-10 \mathrm{y},{ }^{\mathrm{c}}:$ Giza \& Qalyubia

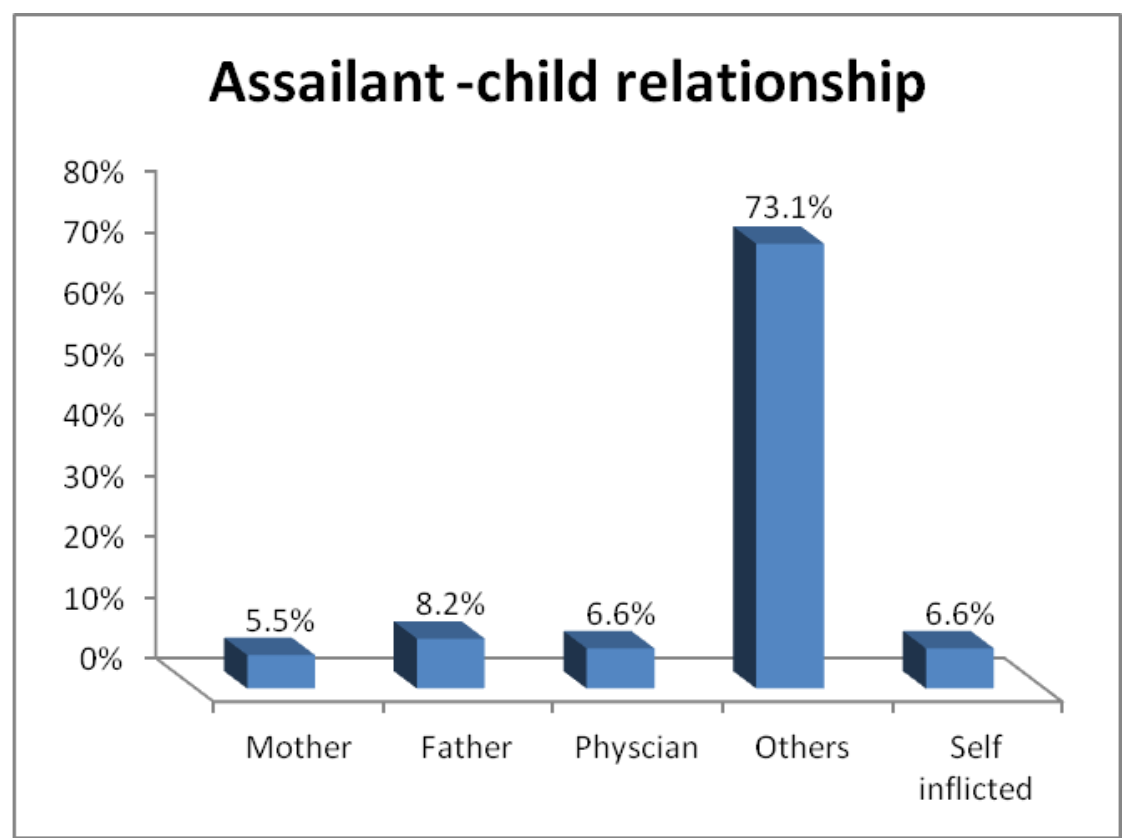

Figure 1.Distribution of the assailant-child relationship 


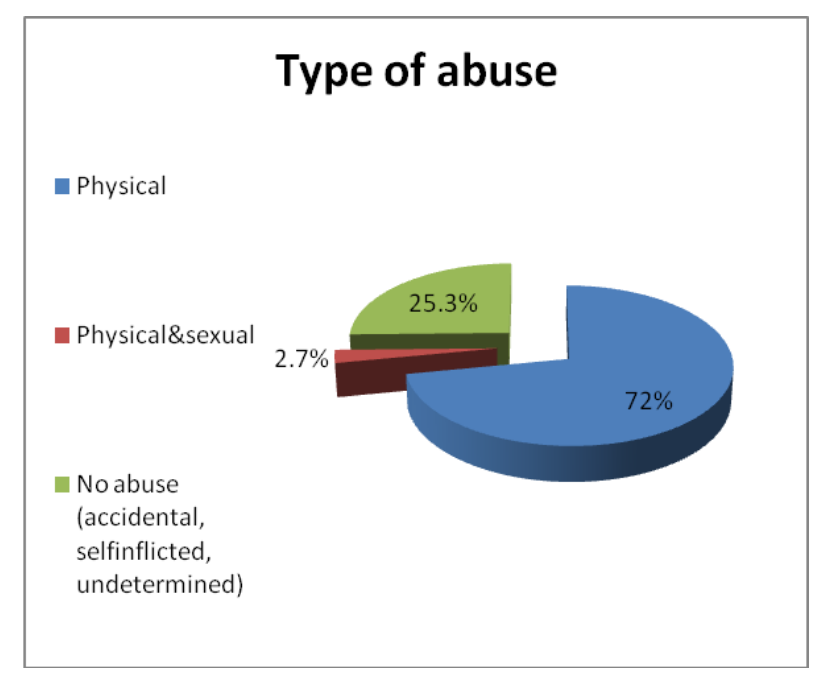

Figure 2. Distribution of the type of abuse

Table 2: Distribution of child deaths according to who reported the incident, the caregiver responsible for the child, the relation of assailant to child and the type of abuse:

\begin{tabular}{|c|c|c|}
\hline & $n$ & $\%$ \\
\hline \multicolumn{3}{|l|}{ Who reported the incident } \\
\hline Parents & 78 & 42.9 \\
\hline Hospital & 18 & 9.9 \\
\hline Passing people or Others & 86 & 47.3 \\
\hline Total & 182 & 100 \\
\hline \multicolumn{3}{|c|}{ Caregiver responsible for child } \\
\hline Undetermined & 56 & 30.8 \\
\hline Parent & 109 & 59.9 \\
\hline Others & 17 & 9.3 \\
\hline Total & 182 & 100 \\
\hline \multicolumn{3}{|l|}{ Relation of assailant to child } \\
\hline Mother & 10 & 5.5 \\
\hline Father & 15 & 8.2 \\
\hline Physician & 12 & 6.6 \\
\hline Others & 133 & 73.1 \\
\hline Self-inflicted & 12 & 6.6 \\
\hline Total & 182 & 100 \\
\hline \multicolumn{3}{|l|}{ Type of abuse } \\
\hline Physical & 131 & 72 \\
\hline Physical \& sexual & 5 & 2.7 \\
\hline No abuse & 46 & 25.3 \\
\hline Total & 182 & 100 \\
\hline
\end{tabular}

$n=$ number of cases 
Table 3: Distribution of The type of crime and the relation between type of crime and age group

\begin{tabular}{|c|c|c|c|c|c|c|c|c|c|}
\hline \multirow{3}{*}{ Type of crime } & \multirow{2}{*}{\multicolumn{2}{|c|}{ Total cases }} & \multicolumn{6}{|c|}{ Age groups } & \multirow[t]{3}{*}{ P value } \\
\hline & & & \multicolumn{2}{|c|}{$\begin{array}{c}{ }^{\mathbf{a}} \text { Infant } \\
n=37\end{array}$} & \multicolumn{2}{|c|}{$\begin{array}{c}{ }^{\mathbf{b}} 1 \text { st decade } \\
n=51\end{array}$} & \multicolumn{2}{|c|}{$\begin{array}{c}\text { 2nd decade } \\
n=94\end{array}$} & \\
\hline & $n$ & $\%$ & $n$ & $\%$ & $n$ & $\%$ & $n$ & $\%$ & \\
\hline No crime & 92 & 50.5 & 19 & 51.4 & 23 & 45.1 & 50 & 53.2 & \\
\hline Fighting/robbery & 44 & 24.2 & 5 & 13.5 & 9 & 17.6 & 30 & 31.9 & \\
\hline Honor/illegal child & 8 & 4.4 & 3 & 8.1 & 2 & 3.9 & 3 & $3.2 \%$ & \\
\hline Malpractice claim & 12 & 6.6 & 6 & 16.2 & 6 & 11.8 & 0 & 0 & $<0.001^{*}$ \\
\hline Sexual assault & 6 & 3.3 & 0 & 0 & 1 & 2 & 5 & 5.3 & \\
\hline Undetermined & 20 & 11 & 4 & 10.8 & 10 & 19.6 & 6 & 6.4 & \\
\hline Total & 182 & 100 & 37 & 20.4 & 51 & 28 & 94 & 51.6 & \\
\hline
\end{tabular}

$n=$ number of cases, $*$ : significant, ${ }^{\mathrm{a}}: 0-2 \mathrm{y},{ }^{\mathrm{b}}: 2-10 \mathrm{y}$

Table 4: Distribution of manner of death and the relation of manner of death and gender

\begin{tabular}{|c|c|c|c|c|c|c|c|}
\hline \multirow{3}{*}{ Manner of death } & \multirow{3}{*}{$n$} & \multirow{3}{*}{$\%$} & \multicolumn{4}{|c|}{ Gender } & \multirow[t]{3}{*}{ P value } \\
\hline & & & \multicolumn{2}{|c|}{$\begin{array}{l}\text { Male } \\
n=112\end{array}$} & \multicolumn{2}{|c|}{$\begin{array}{c}\text { Female } \\
n=70\end{array}$} & \\
\hline & & & $n$ & $\%$ & $n$ & $\%$ & \\
\hline Pathological & 15 & 8.2 & 9 & 8 & 6 & 8.6 & \\
\hline Homicidal & 62 & 34.1 & 47 & 42 & 15 & 21.4 & \\
\hline Suicidal & 26 & 14.3 & 7 & 6.2 & 19 & 27.1 & $<0.001 *$ \\
\hline Accidental & 52 & 28.6 & 33 & 29.5 & 19 & 27.1 & .0 .001 \\
\hline Difficult labor, prematurity, malpractice & 27 & 14.8 & 16 & 14.3 & 11 & 15.7 & \\
\hline Total & 182 & 10 & 112 & 61.5 & 70 & 38.5 & \\
\hline
\end{tabular}

$n=$ number of cases, *: significant 


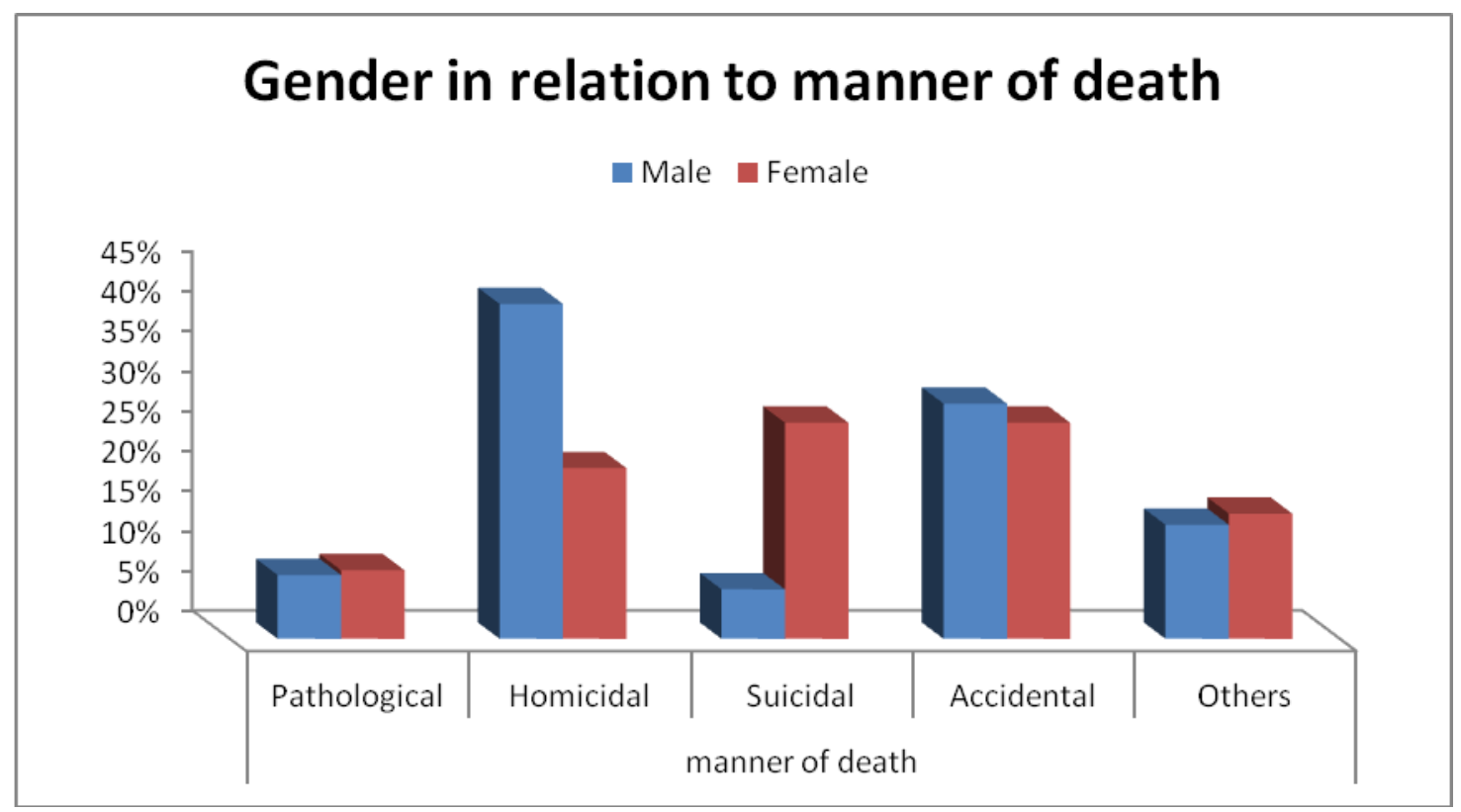

Figure 3. Relation of gender to manner of deaths

Table 5: Distribution of clothes state and external examination findings of child deaths

\begin{tabular}{lcclcc}
\hline \multicolumn{1}{c}{ Clothes } & $\boldsymbol{n}$ & $\boldsymbol{\%}$ & External findings & $\boldsymbol{n}$ & $\boldsymbol{\%}$ \\
\hline & & & & & \\
Not mentioned & 7 & 3.8 & No findings & 48 & 26.4 \\
No tears or blood & 85 & 46.7 & Blunt trauma & 74 & 40.7 \\
Tears, burn or blood & 27 & 14.8 & penetrating trauma & 22 & 12.1 \\
Naked & 43 & 23.6 & decomposition & 11 & 6 \\
Wet & 8 & 4.4 & thermal injury & 23 & 12.6 \\
Gown & 12 & 6.6 & old scars & 2 & 1.1 \\
Total & 182 & 100 & bleeding & 2 & 1.1 \\
& & & & & \\
\hline$n=$ number of cases & & & & &
\end{tabular}


Table 6: Distribution of child deaths according to the regional injury and extravasations

\begin{tabular}{lcclcc}
\hline Regional injury & $\boldsymbol{n}$ & $\boldsymbol{\%}$ & Extravasations & $\boldsymbol{n}$ & $\boldsymbol{\%}$ \\
\hline Head & 29 & 16 & Yes & 103 & 56.6 \\
Neck & 9 & 5 & No & 79 & 43.4 \\
Chest & 21 & 11.5 & & 182 & 100 \\
& 7 & 4 & & & \\
Abdomen & 6 & 3.3 & & & \\
Lower limb & 80 & 44 & & & \\
Multiple regions including genitalia & 30 & 16.2 & & & \\
No injury & 182 & 100 & & &
\end{tabular}

$n=$ number of cases

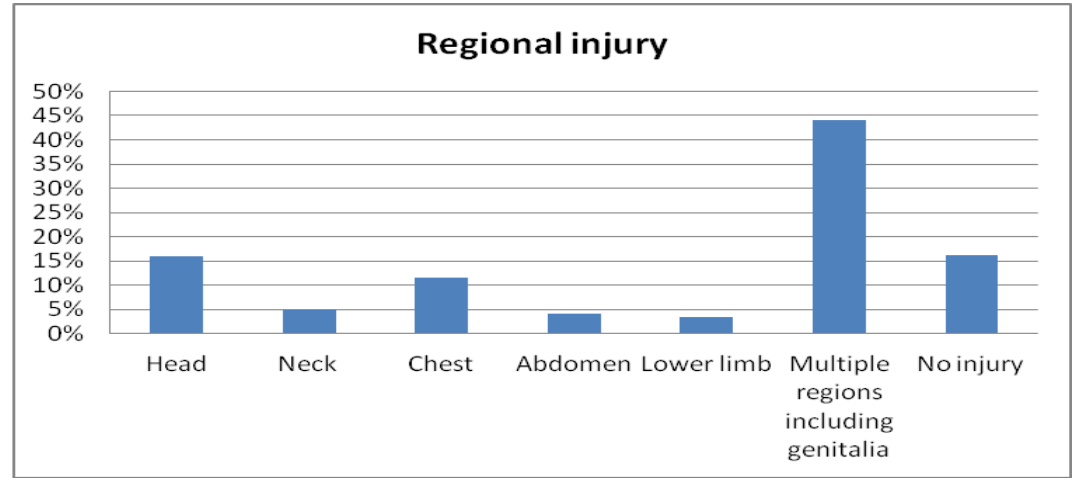

Figure 4.Distribution of child deaths according to the regional injury

Table 7: Distribution of child deaths with head, neck, chest and abdominal injuries

\section{Head and neck injuries}

Skull fracture

Extradural hemorrhage

Subdural hemorrhage

Subarachnoid hemorrhage

Cerebral contusion/laceration/edema/infection

Meningeal hemorrhage

Hyoid fracture

Vascular injury (Neck)

\section{n $\%$ Chest and abdominal injuries}

$28 \quad 15.4 \quad$ Fracture ribs

12 6.6 Lung/heart laceration/ congestion

$\begin{array}{ll}18 & 9.9\end{array}$

$14 \quad 7.7 \quad$ Hemo-/pneumo-thorax/pneumonia/pus $42 \quad 23.1$

$10 \quad 5.5$ Soot in airway

$3 \quad 1.6$

6033

Abdominal organ

$36 \quad 19.8$

$5 \quad 2.7 \quad$ Hemoperitoneum

$24 \quad 13.2$

$\begin{array}{ll}15 & 8.2\end{array}$

$10 \quad 5.5$

$n=$ number of cases 


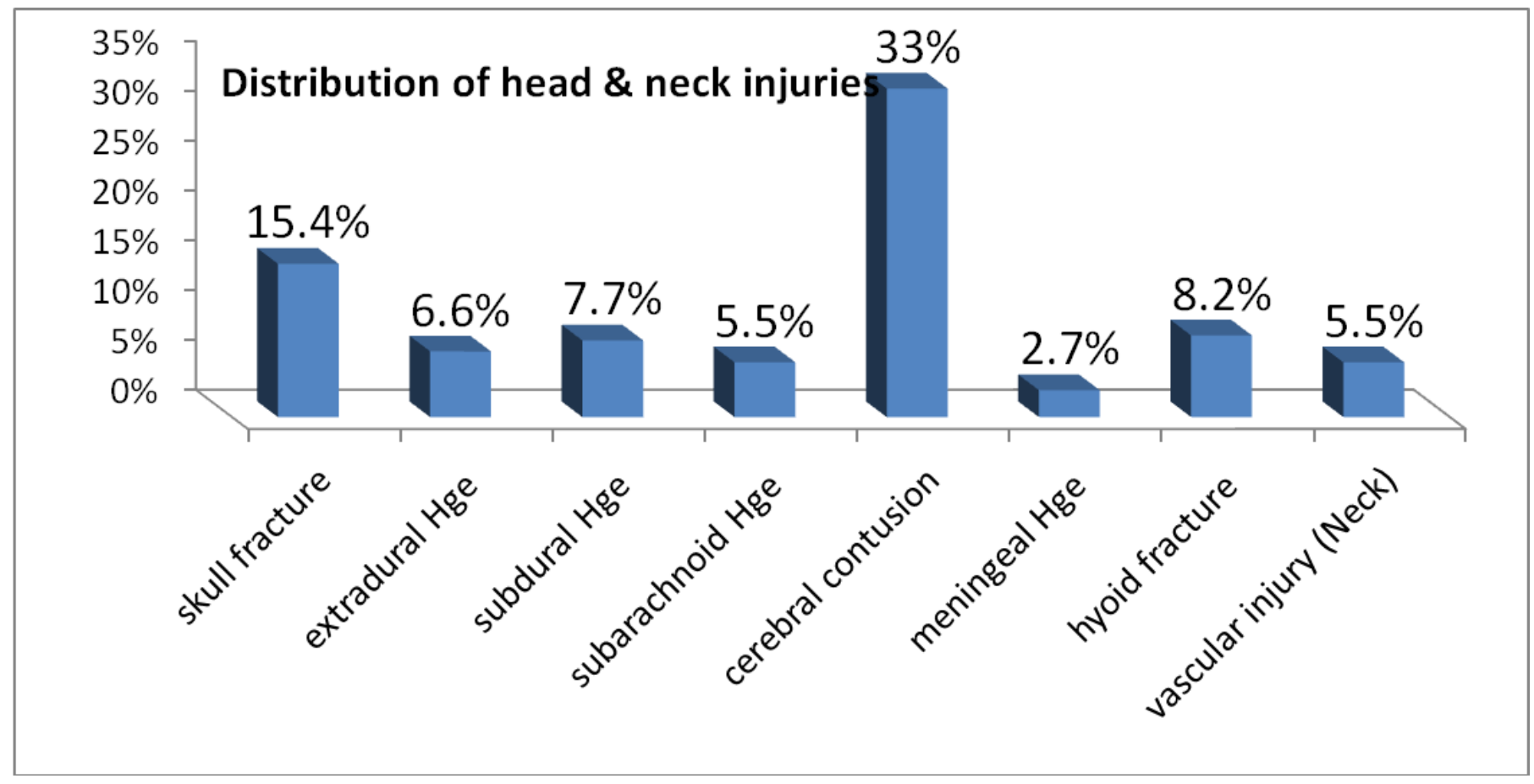

Figure 5. Distribution of child deaths with head and neck injuries

Table 8: The relation between different regional injuries and age groups

\begin{tabular}{|c|c|c|c|c|c|c|c|c|}
\hline \multirow{3}{*}{ Regional injury } & & \multicolumn{6}{|c|}{ Age groups } & \multirow{3}{*}{ P value } \\
\hline & & \multicolumn{2}{|c|}{$\begin{array}{c}{ }^{\mathbf{a}} \text { Infant } \\
n=37\end{array}$} & \multicolumn{2}{|c|}{$\begin{array}{c}\text { b 1st decade } \\
n=51\end{array}$} & \multicolumn{2}{|c|}{$\begin{array}{c}\text { 2nd decade } \\
n=94\end{array}$} & \\
\hline & & $n$ & $\%$ & $n$ & $\%$ & $n$ & $\%$ & \\
\hline \multirow{2}{*}{ Subarachnoid hemorrhage } & Yes & 6 & 16.2 & 2 & 3.9 & 2 & 2.1 & \multirow{2}{*}{$0.008 *$} \\
\hline & No & 31 & 83.8 & 49 & 96.1 & 92 & 97.9 & \\
\hline \multirow{2}{*}{ Hyoid fracture } & Yes & 0 & 0 & 2 & 3.9 & 13 & 13.8 & \multirow{2}{*}{$0.013 *$} \\
\hline & No & 37 & 100 & 49 & 96.1 & 81 & 86.2 & \\
\hline \multirow{2}{*}{ Fracture ribs } & Yes & 1 & 2.7 & 2 & 3.9 & 15 & 16 & \multirow{2}{*}{$0.019 *$} \\
\hline & No & 36 & 97.3 & 49 & 96.1 & 79 & 84 & \\
\hline \multirow{2}{*}{ Lung/heart laceration/ congestion } & Yes & 10 & 27 & 12 & 23.5 & 40 & 42.6 & \multirow{2}{*}{$0.042 *$} \\
\hline & No & 27 & 73 & 39 & 76.5 & 54 & 57.4 & \\
\hline \multirow{2}{*}{ Hemoperitoneum } & Yes & 5 & 13.5 & 2 & 3.9 & 17 & 18.1 & \multirow{2}{*}{$0.04 *$} \\
\hline & No & 32 & 86.5 & 49 & 96.1 & 77 & 81.9 & \\
\hline
\end{tabular}

$n=$ number of cases, $*$ : significant, ${ }^{\mathrm{a}}: 0-2 \mathrm{y},{ }^{\mathrm{b}}: 2-10 \mathrm{y}$ 
Table 9: Distribution of child deaths with upper and lower limb injuries

\begin{tabular}{lll}
\hline Upper and lower limb injuries & $\boldsymbol{n}$ & $\boldsymbol{\%}$ \\
\hline Upper limb fracture & 6 & 3.3 \\
Upper limb muscle injury & 6 & 3.3 \\
Upper limb vascular injury & 1 & 0.5 \\
Lower limb fracture & 11 & 6 \\
Lower limb muscle injury & 7 & 3.8 \\
Lower limb vascular injury & 6 & 3.3 \\
\hline$n=$ number of cases & &
\end{tabular}

Table 10: Distribution of used weapon in child deaths and the relation between the used weapon and gender

\begin{tabular}{|c|c|c|c|c|c|c|c|}
\hline \multirow{3}{*}{ Underlying cause of death } & \multirow{3}{*}{$n$} & \multirow{3}{*}{$\%$} & \multicolumn{4}{|c|}{ Gender } & \multirow{3}{*}{$P$ value } \\
\hline & & & \multicolumn{2}{|c|}{$\begin{array}{l}\text { Male } \\
n=112\end{array}$} & \multicolumn{2}{|c|}{$\underset{n=70}{\text { Female }}$} & \\
\hline & & & $n$ & $\%$ & $n$ & $\%$ & \\
\hline $\begin{array}{l}\text { Malpractice claims/ } \\
\text { pathological deaths }\end{array}$ & 52 & 28.6 & 27 & 24.1 & 25 & 35.7 & \\
\hline Wounds & 70 & 38.4 & 50 & 44.7 & 20 & 28.5 & \\
\hline Blunt & 37 & 20.3 & 25 & 22.4 & 12 & 17.1 & \\
\hline Sharp & 18 & 9.9 & 13 & 11.6 & 5 & 7.1 & \\
\hline Firearm & 15 & 8.2 & 12 & 10.7 & 3 & 4.3 & $0.044 *$ \\
\hline Poison & 7 & 3.8 & 2 & 1.8 & 5 & 7.1 & \\
\hline Asphyxia & 30 & 16.5 & 21 & 18.8 & 9 & 12.9 & \\
\hline Thermal injury & 23 & 12.6 & 12 & 10.7 & 11 & 15.7 & \\
\hline Total & 182 & 100 & 112 & 61.5 & 70 & 38.5 & \\
\hline
\end{tabular}

$n=$ number of cases, *: significant 


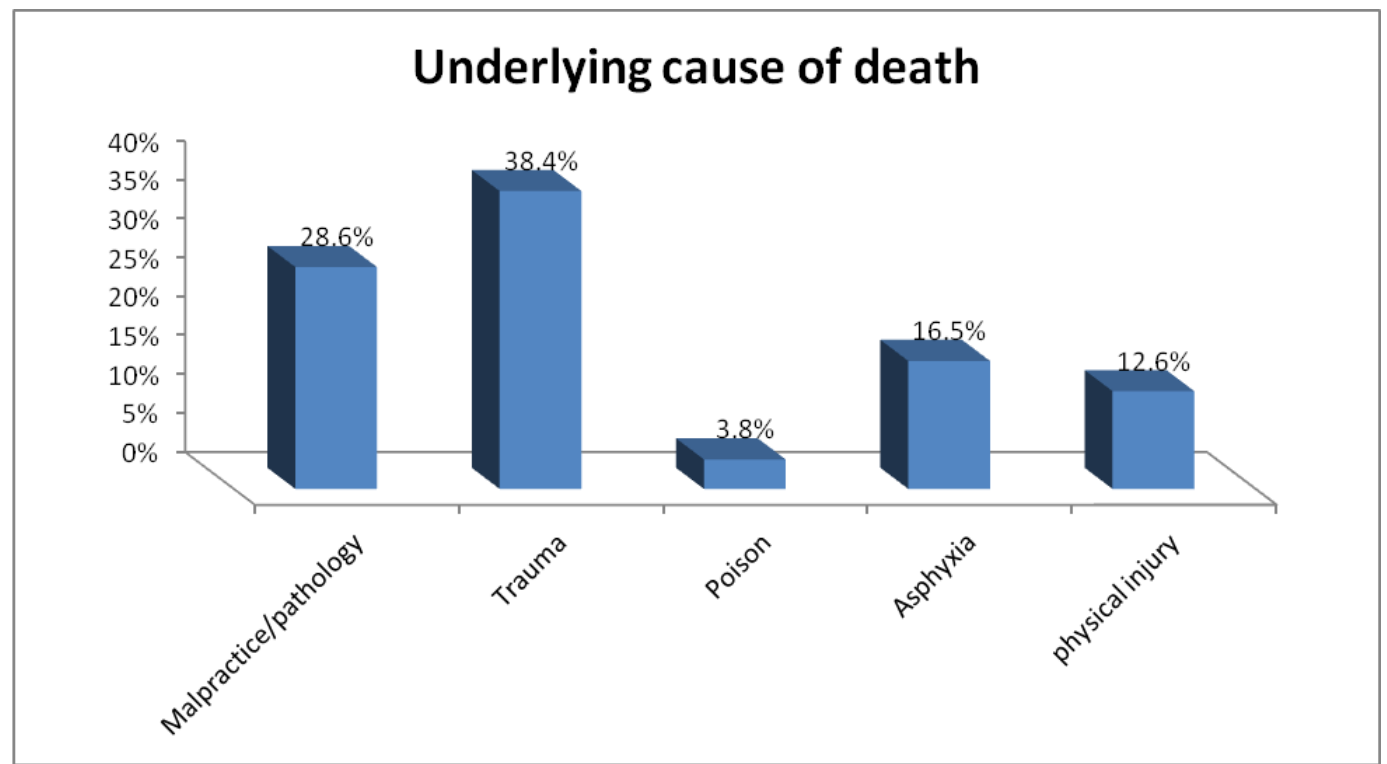

Figure 6. Distribution of the underlying cause of death among the studied cases

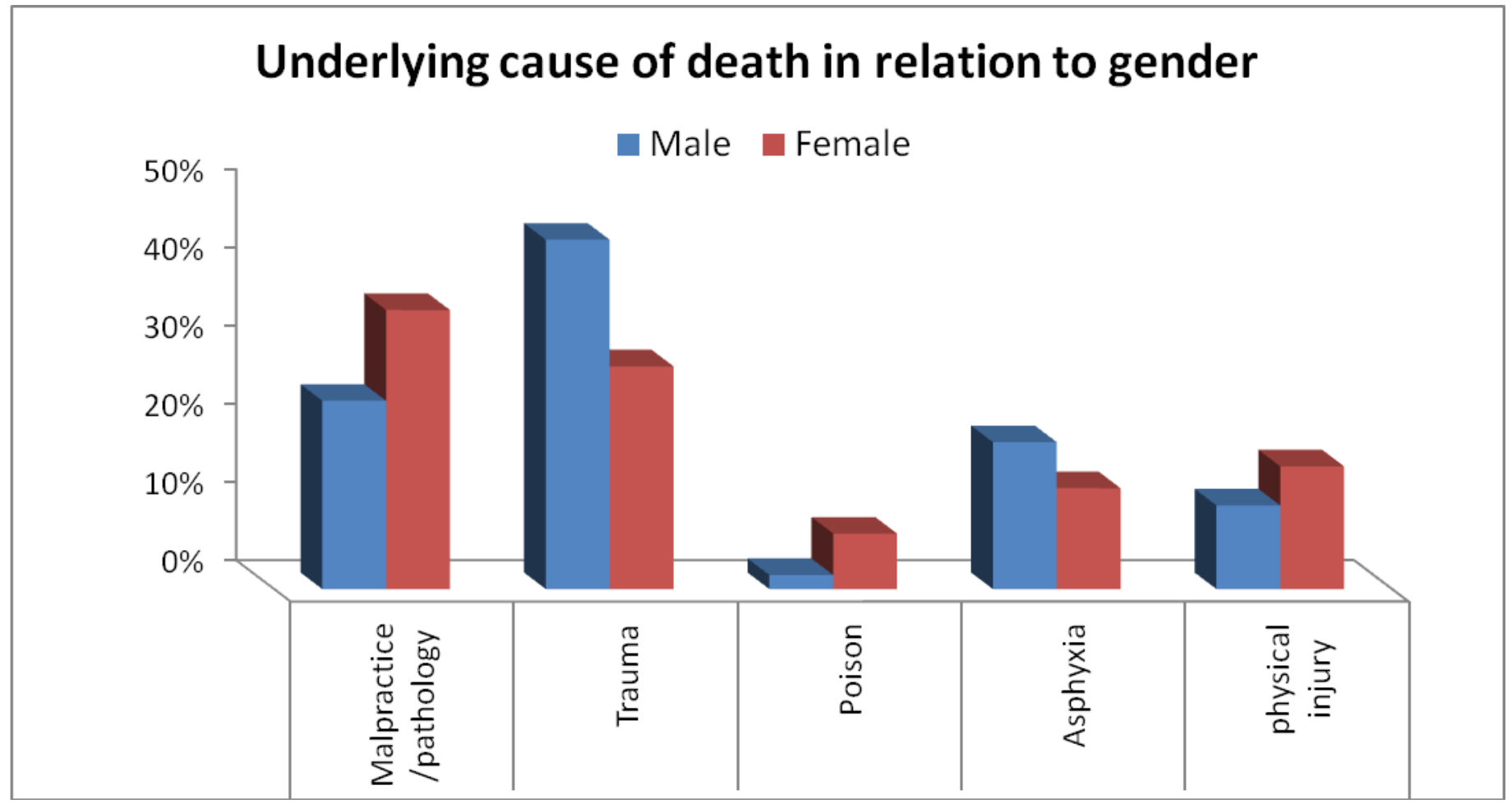

Figure 7. Relation between the underlying cause of death and gender 
Table 11: Distribution of cause of death in child deaths

\begin{tabular}{lll}
\hline \multicolumn{1}{c}{ Cause of death } & $\boldsymbol{n}$ & $\mathbf{\%}$ \\
\hline & & \\
Not documented/ Unknown & 20 & 11 \\
Cardiovascular failure & 65 & 35.7 \\
Central nervous system failure & 31 & 17 \\
Respiratory failure & 66 & 36.3 \\
Total & 182 & 100 \\
& & \\
\hline$n=$ number of cases & &
\end{tabular}

Table 12: Distribution of laboratory findings in child deaths and Distribution of cases with positive laboratory findings

\begin{tabular}{lcclll}
\hline Laboratory Findings & $\boldsymbol{n}$ & $\boldsymbol{\%}$ & Laboratory Findings of +ve cases & $\boldsymbol{n}$ & $\boldsymbol{\%}$ \\
\hline \multirow{2}{*}{ Not available } & & & & & \\
+ve & 50 & 27.5 & Semen & 6 & 25 \\
-ve & 24 & 13.2 & Co & 12 & 50 \\
Total & 108 & 59.3 & Organophosphates & 1 & 4.2 \\
& 182 & 100 & Tramadol & 4 & 16.7 \\
& & & Hashish & 1 & 4.2
\end{tabular}

$n=$ number of cases

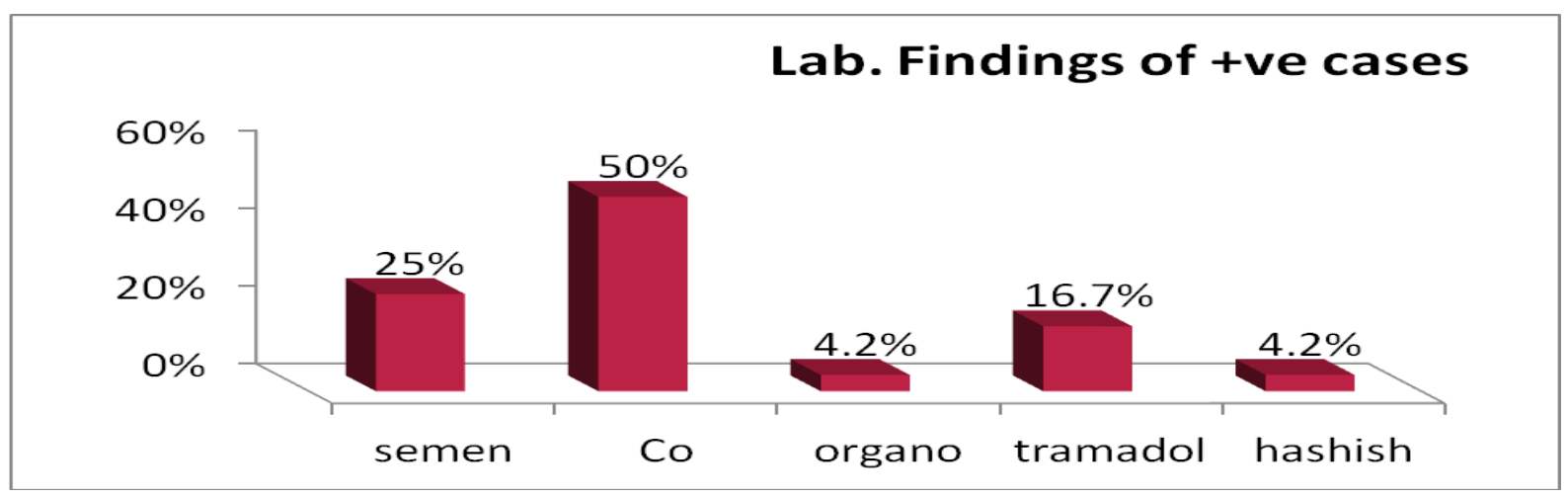

Figure 8. Distribution of cases with positive laboratory findings 


\section{DISCUSSION}

Abusive behavior at home is a human rights crime and a costly public health problem all over the world. The grave impact of violence affect all countries. Consistently, it causes over 1.6 million deaths per year (Haddad et al., 2011).

Incidence of homicides is constantly changing as it`s closely related to socioeconomic changes within a particular community (Baralic et al., 2010). Various factors may increase the child deaths incidence, such as overpopulation, daily life depression, revolution, terrorism, drug abuse and easy accessibility for weapons (Patel, 2012).

Unfortunately, Egypt has no reliable statistics about the child deaths. So, the aim of this study was to draw attention to socio demographics, characteristics, autopsy findings and laboratory results of such cases in Great Cairo through the year 2016 in order to achieve Knowledge base for detection and assessing child deaths and thus proper documentation of such phenomena hoping to decrease such crimes.

The total number of autopsied cases was 1562 in Great Cairo during the year of the present study. 182 of these cases were children representing (11.7\%).

This is higher than the percent had been recorded in Port-Said and North Sinai during the period from 2000 to 2007 which was 89 representing $2.73 \%$ of the total deaths (El-Elemi and Moustafa, 2013).

This may be clarified by the culture of Port-Said and North Sinai that consider notification to authorities is a dishonorable conduct or may be due to lack of data base, also the use of traditional solving of domestic troubles in Arabian sitting may have a role.

Concerning the seasonal variation in our study it was found that, the highest incidence of Child deaths was observed during Summer (36.8\%).

The rate of crimes tends to be higher in the summer than during other seasons of the year due to a variety of factors, including the following: Better weather during the warmer months means more people are out and about, including more thieves and burglars. Also, Warm weather encourages people to enjoy outdoor activities before colder weather arrives. Empty homes more often give criminals an ideal chance for stake out and breaking in. In fact, the heat can make some people irritable. It's possible that the discomfort caused by elevated temperatures can contribute to a rise in criminal behavior, which can lead to crime.

Opposite results were reported by AlHawari and El-Banna, (2017) who stated that, spring months had the highest percentage of child deaths $(28.1 \%)$, then they declined throughout winter and summer months $(25.8 \%$ and $25 \%$ respectively), to reach $21.1 \% \%$ in autumn months

The higher hospital admissions, mood disorder severity, electroconvulsive therapy use, and worsening of depression scores in spring may point out a connection between spring and aggravation of mood disorders (Goodwin 
\& Jamison 2007, Postolache et al. 2010).

The current study revealed that the highest percentage of child deaths was found in the age group between $10-18$ years that represents 94 case $(51.6 \%)$.

Similar results were observed by Kotb and Ibrahim, (2014) and Athani et al, (2017) who found that, the highest percentage of child deaths was mainly in the age groups between $16-18$ years and 15-18 respectively.

The high incidence in this age group is because they are prone to commit suicide and they use different means of transportations, so they are also more prone to road traffic accidents.

Findings of the current work are not in agreement with those of El-Elemi and Moustafa,(2013) who stated that, $41 \%$ of the victims were less than 1 year old.

This may be due to that infanticide cases are mostly not reported in official records if the delivery was unattended or performed outside hospitals.

By analyzing the child deaths gender in the present study, the number of male cases was 112 representing $61.5 \%$ of cases and 70 cases were females which represents $38.5 \%$ of cases. Our results were similar to studies of Cekin et al., (2005) and Parkkari et al., (2017) where males outnumbered females because of their more adventurous nature, violent attitude and open-air activities like swimming, riding motorcycles and the motor tricycle (toktok).
On the other hand, this observation is in contrast to previous studies which found that female infants are particularly at risk for infanticide (Byard, 2004). In China, it was reported that girls are more prone to be killed at birth or particularly aborted because of their perceived decreased societal value, leading to a marked imbalance in the male : female ratio (Coale and Banister, 1994).

The present study revealed that 103 cases $(56.6 \%)$ of child deaths reside Cairo while 79 cases $(43.4 \%)$ of cases reside Giza and Qalyubia. Similar to kotb and Ibrahim, (2014), Kajese et al., (2011) and El-Hak et al., (2009) who found that more than $50 \%$ of victims were from rural areas with low socioeconomic status.

This result is in contrast with the results of El-Elemi and Moustafa, (2013) who documented that $73 \%$ of victims were from urban areas with moderate and high socioeconomic levels.

In the current work, the assailant was either a stranger or a relative in 133 cases $(73.1 \%)$, father was the assailant in 15 cases $(8.2 \%)$ while mother was only in 10 cases $(5.5 \%)$.

Schnitzer and Ewigman, (2005) stated that, children living with unrelated adults were 50 times more prone to fatal injury than were children living with their parents. These results are in accordance with a study done in Belgrade, in which $69.4 \%$ of the victims were murdered by relative (Baralic et al., 2010).

Meanwhile, the study of El-Elemi and Moustafa, (2013) showed that the assailant was a stranger in (45\%), 
colleague or neighbor in $(22.5 \%)$, and a first degree family member in $(9 \%)$ of cases.

On the other hand, the Turkish study by Karakus et al., (2003), indicated that mothers were the assailant in $70 \%$ of cases. Also Baralic et al., (2010), reported that more than half of the victims $(69.4 \%)$ were killed by parents. The mother was the single assailant in most of these cases (52.2\%). Seemingly, Kotb and Ibrahim, (2014) showed that the majority of known assailants were the child's relative and neighbors $(58 \%)$ and the parents outnumbered other relative assailant.

In our study the fathers outnumbered the mothers as single assailant in the child abused cases, similar to a study done in malysia which reported that mothers are less likely to kill their children in developing countries (Kasim et al., 1995).

This parents engagement in such fatal injuries may be due to that, Egyptian parents will in general use force through beating to discipline the child, particularly when the child shows troublesome behavior, law-breaking and noncompliance at home or school. This could increase in severity and may be lethal in low socio-economic families (Atta and Youssef, 1998).

The physical abuse was the commonest type of violence (131 cases, $72 \%$ ) as compared to 5 cases $(2.7 \%)$ who were subjected to combined physical and sexual abuse.

These findings are contradictory with those of Al-Hawari and El-Banna,
(2017) who reported that, sexual abuse was the commonest type. This difference may be because Al-Hawari and El-Banna study included alive cases of different age groups subjected to domestic violence only in South region of Jordan.

Fighting or roberry was the commonest type of crime representing 44 cases. 30 cases of them were in second decade. The teenagers are more prone to outdoor violence as they are more independant from their parents than first decade children, the researchers of the current study also recorded a number of cases in which the teenager was a toktok driver (motor tricycle) and the violence was inflicted to facilitate robbery.

Crimes of honor/illegal child were reported in 8 cases of which 3 cases were in the second decade, 2 cases in the first decade and 3 cases were infants.

These findings were very serious as crimes of honor in Egypt appear to recieve insignificant attention. A number of studies on honor crimes by the Center for Islamic and Middle Eastern Law at the School of Oriental and African Studies in London include a study on the legal system in Egypt, noting the bias against women in favor of men in general, and in particular Article 17 of the Penal Code Egyptian: discretionary power to allow toleration in certain circumstances, often used in the case of honor crimes (Cusak and Cook, 2007).

The analysis of manner of death was based on history, eye witnesses, police information, circumstantial evidence and the autopsy findings,. Our study revealed that $34.1 \%$ of cases were homicidal, 
$28.6 \%$ were accidental and $14.3 \%$ were suicidal.

Number of male victims was higher than females in homicidal and accidental deaths, while suicidal deaths were more in females.

Our results are partially in line with the study conducted by Kotb and Ibrahim, (2014) where homicidal deaths $(42.5 \%)$ were more than accidental deaths $(36.4 \%)$ and suicidal were the least. In spite of the fact that men will in general complete suicide more often than women, women attempt suicide far more frequently than men. This pattern is frequently referred to as the "gender paradox" of suicidal behavior (Beautrais, 1996).

Our results were in contrast with Athani et al., (2017) who found accidental cases were more than suicides. this contrast could be due to different socio-behavioral tendency related to each country.

External examination of the studied cases reveled that blunt injury (abrasion, contusion, contused wound) was the commonest type observed in 74 cases, followed by thermal injuries in 23 cases then penetrating injury in 22 cases. These findings are supported by Subedi et al., (2013).

As for the site of trauma, the current study showed that, multiple regions were mostly involved in 80 cases (44\%) including 3 cases with injury to genitalia. Head was the region with highest number of injuries (29 cases, 16\%) followed by the chest 21 cases $(11.5 \%)$, while neck, abdomen and lower limb injuries presented 9 cases (5\%), 7 cases (4\%) and 6 cases $(3.3 \%)$ respectively. 30 cases (16.2\%) revealed negative autopsy findings. Extravasations was observed in 103 cases $(56.6 \%)$.

Similar results were reported by ElHak et al., (2009) and Okoye and Okoye, (2011) who found that abusive head trauma was the commonest type of injury. Our studies are also in accordance with those of Kotb and Ibrahim, (2014) who observed that, multiple regions were injured in most cases, while head showed the greatest number of injuries, followed by the neck.

On analyzing cases with head injuries; cerebral contusion or laceration was the commonest, representing 33\%, followed by skull fractures $15.4 \%$, then subdural, extradural, subarachnoid and combined meningeal hemorrhage in $7.7 \%$, $6.6 \%, 5.5 \%$ and $2.7 \%$ respectively. While, neck injuries were in the form of hyoid fracture $8.2 \%$ and vascular injury $5.5 \%$.

This is in contrast with Gill et al., (2009) who conducted a study on infant and revealed that subdural and subarachnoid hemorrhage was more common than skull fractures in head injury deaths.

This contrast could be attributed to type of trauma as head injuries may involve contact and/or accelerationdeceleration forces. Contact forces cause focal lesions (scalp contusion, skull fracture, epidural hemorrhage), while acceleration-deceleration (mainly rotational forces) results in diffuse lesions (e.g., subdural hemorrhage, diffuse 
axonal injury, intermediate contusion) (Gill et al., 2009).

subarachnoid hemorrhage showed statistically significant higher $\%$ in infants as compared to other age groups. Hochstadter et al., (2014) retrospectively analyzed 171 cases of severe traumatic brain injury (TBI), children who had CT head imaging within the first $24 \mathrm{~h}$ of hospital admission. Subarachnoid hemorrhage was present in $50 \%$ children with severe TBI, and it was indicative of TBI severity.

On considering cases with chest injuries; lung or heart laceration was the commonest (62 cases), followed by hemo/pneumo thorax then fracture ribs. The lungs occupy most of the rib cage, and thus are probably more vulnerable to injury when compared to the heart. This is in line with the studies done on road traffic incident victims in India by Kumar et al., (2011) and Reddy et al., (2014).

Visceral laceration and hemoperitoneum were manifested in most of the cases with abdominal injuries (36 and 24 respectively). The abdomen is vulnerable to injury since there is minimal bony protection for underlying organs. This is supported by Subedi et al., (2013) who studied the profile of abdominal and pelvic injuries in medicolegal autopsy in Nepal.

On evaluating cases with limb injuries; lower limb injuries were more common than upper limb. This result is supported by Enweluzo et al., (2008).
Regarding the underlying cause of death in the current study, trauma was the commonest cause of death (38.4\%), while $28.6 \%$ of cases were due to various malpractice claims and pathological deaths. Asphyxia was the third cause in $16.5 \%$ of cases followed by thermal injuries in $12.6 \%$, and the least cause was due to poison in $3.8 \%$ of cases.

These results are partially supported by those of Kotb and Ibrahim, (2014) who documented that trauma was the commonest cause of death, followed by asphyxia, pathological causes then poisoning and Burns. El-Hak et al., (2009) also reported in their study in Egypt that trauma was the most common cause of death in childhood.

Regarding to the underlying cause of death in relation to gender, males showed statistically significant higher incidence of death with asphyxia, blunt injury, penetrating injury, thermal injury and firearm than females. While, females showed statistically significant higher incidence than males with death by poison, this may be explained by the aggressive nature of males.

Consistently, in 2017 a study conducted in USA reported that males ages 15 to 19 were more than seven times more likely to die from firearm-related incidents (CDC, 2017).

As for, the type of wound in the current study, blunt injury (bruises and lacerations) was the commonest type followed by sharp injury (cut and stab wounds) and firearm injury was the least. The high rate of using blunt objects could be clarified by the easy accessibility to 
such objects at a particular moment in time (these include stick, fists and feet and other bodily parts of the perpetrator) (Baralic et al., 2010).

These observations are in line with a study in Nebraska, where injuries were due to blunt-force trauma $(32 \%)$ followed by asphyxia (26\%) (Okoye and Okoye, 2011).

Considering the cases with positive laboratory findings of poisoning, $50 \%$ of these cases were positive for carbon monoxide, $16.7 \%$ and $4.2 \%$ were positive for drugs of abuse (tramadol and hashish) respectively and only $4.2 \%$ were positive for organophosphate.

These results agree with those of Kotb and Ibrahim, (2014) which showed that $42 \%$ of poisoning cases were by organophosphorus, followed by carbon monoxide intoxication in $36.8 \%$ and $21 \%$ of cases showed drugs of abuse.

Child abuse is a global phenomenon occurring in all socio-economic classes. Yet, it is still underrated and unrecorded due to poor cooperation (Jenny and Isaac, 2006). This frequently resulted in failure to explain the phenomenon of child abuse and deaths. Commonly, the degree of child abuse and deaths in Arab countries is not well recognized (HajYahia and Shor, 1995).

Collaboration of different authorities is needed to Document the actual incidence and details of child abuse and deaths cases.

\section{CONCLUSION AND RECOMMENDATIONS}

Although great efforts has been made in child survival mainly in the past decade, it has not been enough. Millions of child deaths are caused by avoidable causes while we have the means to deliver affordable interventions. The growing motivation towards strengthening of national civil registration in developing countries carries great guarantee for improvement of the accuracy and precision of child cause-of-death rating. From this work we concluded that the total number of child deaths during one year period in the Great Cairo was 182 cases. Majority of incidents were in summer, over $50 \%$ of cases were males in the 2nd decade, the perpetrator was not related to the victim in more than $70 \%$ of incidents, $70 \%$ of cases showed physical abuse. Male children deaths were mainly of homicidal or accidental nature, while females were of suicidal nature. Weapons related deaths in males were mainly blunt, sharp or firearm, while in females it was either poison or thermal agent. 50\% of cases with +ve toxicologic lab findings showed elevated Co levels followed by drugs of abuse. On autopsy, cases showed higher incidence of cerebral contusion and skull fracture, followed by lung or heart laceration and lower limb fractures. Urgent attention is required to take the problem of injury and violence against children and adolescents occurring through the world. In Egypt specifically, driving toktok should be prohibited for the children below 18 years. There has been a great shift in the epidemiological patterns of child deaths. Although great progress has been made in prevention of infectious diseases, the exposure of children and adolescents to the risk of injury and violence has been increasing 
and is projected to continue in the future. Internationally, the focus of child heath interventions has been made to reduce the under 5 child mortality rate, but the children between 5 and 20 unfortunately received limited attention, which is of particular concern, given that injuries during this period, constitute the greatest burden.

\section{DECLARATIONS}

\section{ETHICS APPROVAL CONSENT TO PARTICIPATE \\ AND}

Research was performed with the approval of Research Ethics Committee at faculty of Medicine for Girls Al-Azhar University (Committee's reference number is 2018122001). Data access permission has been issued from the Egyptian Forensic Medicine authority. Data collection was anonymous.

\section{CONSENT FOR PUBLICATION}

Not applicable

\section{COMPETING INTERESTS}

None of the authors have any competing interests in the manuscript.

\section{REFERENCES}

Al-Hawari, H. and El-Banna, A. (2017):

A medicolegal study of domestic violence in south region of Jordan. Egyptian journal of forensic sciences, 7(1):5.
Association of Chief Police Officers (ACPO). (2014): A guide to investigating child deaths [DOC]. http://library.college.police.uk/docs/a cpo/ACPO-guide-to-investigatingchild-deaths-2014.doc. Accessed 7 June 2019

Athani, P.; Hugar, BS.; Harish, S. and Girishchandra, YP. (2017): Pattern of unnatural deaths among children: an autopsy study. Medico-Legal Journal, 85(2):90-2.

Atta, HA. and Youssef, RM. (1998): Child abuse and neglect: mothers' behavior and perceptions. Eastern Mediterranean Health Journal, 4(3):502-12.

Baralic, I.; Savic, S.; Alempijevic, DM.; Jecmenica, DS.; Sbutega-Milosevic, G. and Obradovic, M. (2010): Child homicide on the territory of Belgrade. Child abuse \& neglect, 34(12):93542.

Beautrais, AL.; Joyce, PR. and Mulder, RT. (1996): Risk factors for serious suicide attempts among youths aged 13 through 24 years. Journal of the American Academy of Child and Adolescent Psychiatry, 35: 11741182.

Brookman, F. and Nolan, J. (2006): The dark figure of infanticide in England and Wales: complexities of diagnosis. J Interpers Violence, 21:869-89.

Byard, WR. (2004): Medicolegal problems with neonaticide in England and Wales: complexities of diagnosis. J Interpers Violence, 21:869-89.

Cekin, N.; Hilal, A.; Gulmen, MK.; Kar H.; Aslan, M. and Ozdemir, MH. (2005): Medicolegal childhood deaths in Adnan, Turkey. Tohoku H Exp Med,206: 73-80. 
Centers for Disease Control and Prevention, National Center for Health Statistics (2017): Underlying Cause of Death 1999-2017 on CDC WONDER [Data tool].

Retrieved

from: http://wonder.cdc.gov/ucdicd10.html. Accessed 30 May 2019

Chan, YH. (2003): Biostatistics 104: Correlational Analysis. Singapore Med J, 44(12):614-619

Coale, AJ. and Banister, J. (1994): Five decades of missing females in China. Demography, 31459-79.

Cordner, SM.; Burke, MP.; Dodd, MJ.; Lynch, MJ.; Ranson, DL. and Robertson, SD. (2001): Issues in child homicides: 11 cases. Leg Med, 3:95-103.

Cusack, S. and Cook, RJ. (2007): "Honor": Crimes, Paradigms, and Violence against Women (review)". Human Rights Quarterly, 29 (2): 524-533.

El-Elemi, AH. and Moustafa, SM. (2013): Review of 89 autopsies of child deaths from violence and neglect in the Suez Canal area, Egypt. Egyptian Journal of Forensic Sciences 3(4):116-22.

El-Hak, SA.; Ali, MA. and El-Atta HM. (2009): Child deaths from family violence in Dakahlia and Damiatta Governorates, Egypt. Journal of forensic and legal medicine, 16(7):388-91.

Enweluzo, GO.; Giwa, SO. and Obalum, DC. (2008): Pattern of extremity injuries in polytrauma in Lagos, Nigeria. Niger Postgrad Med $J, 15(1): 6-9$.

Gill, JR.; Goldfeder, LB.; Armbrustmacher, V.; Coleman, A.;
Mena, H. and Hirsch, CS. (2009): Fatal Head Injury in Children Younger Than 2 Years in New York City and an Overview of the Shaken Baby Syndrome. Arch Pathol Lab Med, 133: 619-627.

Goodwin, FK and Jamison, KR (2007): Sleep and Biological Rhythms "Manic- Depressive Illness: Bipolar Disorders and Recurrent Depression" Oxford University Press, New York; 659-688.

Haddad, L.; Shotar, A.; Younger, JB.; Alzyoud, S. and Bouhaidar, CM. (2011): Screening for domestic violence in Jordan: validation of an Arabic version of a domestic violence against women questionnaire. International Journal of Women's Health, 3:79-86

Haj-Yahia, MM. and Shor, R. (1995): Child maltreatment as perceived by Arab students of social science in the West Bank. Child abuse \& neglect, 19(10):1209-19.

Hochstadter, E.; Stewart, TC.; Alharfi, IM.; Ranger, A. and Fraser, DD. (2014): Subarachnoid hemorrhage prevalence and its association with short-term outcome in pediatric severe traumatic brain injury. Neurocrit Care, 21: 505-513.

Jenny, C. and Isaac, R. (2006): The relation between child death and child maltreatment. Arch Dis Child, 91:265-9.

Kajese, TM.; Nguyen, LT.; Pham, GQ.; Pham, VK.; Melhorn, K. and Kallail, KJ. (2011): Characteristics of child abuse homicides in the state of Kansas from 1994 to 2007. Child Abuse \& Neglect, 35(2):147-54. 
Karakus, M.; Ince, H.; Ince, N.; Arican, N. and Sozen, S. (2003): Filicide cases in Turkey, 1995-2000. Croatian medical journal, 44(5):592-5.

Kasim, MS.; Cheah, I. and Shafie, HM. (1995): Childhood deaths from physical abuse. Child abuse \& neglect, 19(7):847-54.

Kotb, NA. and Ibrahim, SF. (2014): Suspicious child female deaths in Great Cairo and Giza during 20112012. Journal of forensic and legal medicine, 28:25-31.

Kumar, AGV.; Honnungar, RS.; Kumar, TSA. and Hallikeri, VR. (2011): Pattern of chest injuries in road traffic incident victims: a sixyear retrospective study. Med Sci Law, 51: 93-96

Leeb, RT.; Paulozzi, LJ.; Melanson, C.; MPH.; Simon, TR. and Arias, I. (2008): Child maltreatment surveillance: Uniform definitions for public health and recommended data elements. Centers for Disease Control and Prevention, National Center for Injury Prevention and Control. https://www.cdc.gov/violencepreventi on/pdf/CM_Surveillance-a.pdf

Accessed 30 May 2019

Okoye, CN. and Okoye, MI. (2011): Forensic epidemiology of childhood deaths in Nebraska, USA. Journal of forensic and legal medicine, 18(8):366-74.

Parkkari, J.; Kannus, P.; Niemi, S.; Koskinen, S.; Palvanen, M.; Vuori, I. and Järvinen, M. (2000): Childhood deaths and injuries in Finland in 1971-1995. International journal of epidemiology, 29(3):51623.
Patel, DJ. (2012): Analysis of homicidal deaths in and around Bastar region of Chhattisgarh. J Indian Acad Forensic Med, 34(2):139-42.

Postolache, TT.; Mortensen, PB.; Tonelli, LH.; Jiao, X.; Frangakis, C.; Soriano, J. and Qin, P. (2010): "Seasonal spring peaks of suicide in victims with and without prior history of hospitalization for mood disorders". J Affect Disord, 121:8893

Reddy, NB.; Hanumantha; Madithati, P.; Reddy, NN. and Reddy, CS. (2014): An epidemiological study on pattern of thoraco-abdominal injuries sustained in fatal road traffic accidents of Bangalore: Autopsybased study. J Emerg Trauma Shock, 7(2): 116-120.

Schnitzer, PG. and Ewigman, BG. (2005): Child deaths resulting from inflicted injuries: household risk factors and perpetrator characteristics. Pediatrics, 116(5): e687-93.

Subedi, N.; Yadav, BN.; Jha, S.; Paudel, IS. and Regmi, R. (2013): A profile of abdominal and pelvic injuries in medico-legal autopsy. Journal of Forensic and Legal Medicine, 20: 792-796.

Walsh, B. (2005): Investigating Child Fatalities: Portable Guides to Investigating Child Abuse. Office of justice programs. https://www.ncjrs.gov/pdffiles1/ojjdp/ 209764.pdf. Accessed 7 June 2019

World Health Organization. (2003): Guidelines for medico-legal care for victims of sexual violence. WHO: Geneva. https://apps.who.int/iris/bitstream/han 
dle/10665/42788/924154628X.pdf?se quence $=1$ Accessed 7 June 2019.

World Health Organization. (2016): Child maltreatment. https://www.who.int/news-room/factsheets/detail/child-maltreatment.

Accessed 30 May 2019. 


\section{الملخص العربى}

دراسة مرجعية عن وفيات الأطفال بين الحالات المُحالة إلى مصلحة الطب الثرعى المصرية خلال الفترة من يناير حتى

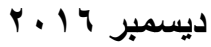

$$
\text { 'إسلام مصطفى فراج' }
$$

$$
\text { ريهام نفاد ب هشام عبد الحميد فرج ج، أمانى عبد الفتاح بيومى ب }
$$

أ قسم الطب الثرعى و السموم الإكلينيكيةـ كلية الطب بنات-جامعة الأزهر، ب قالعم الطب الثرعى و السموم الإكلينيكية كلية

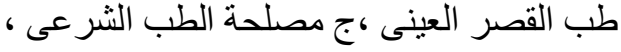

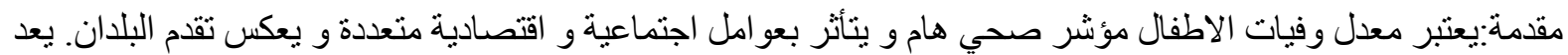

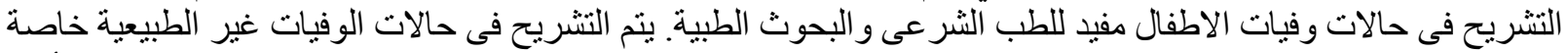

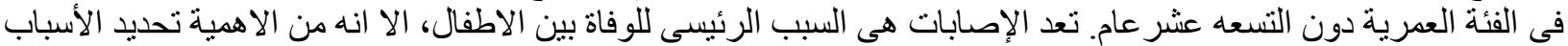

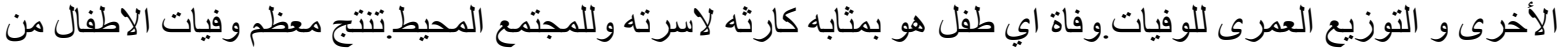

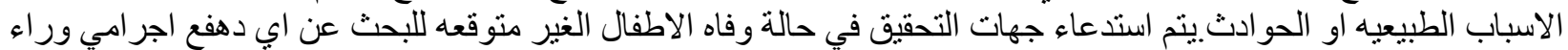

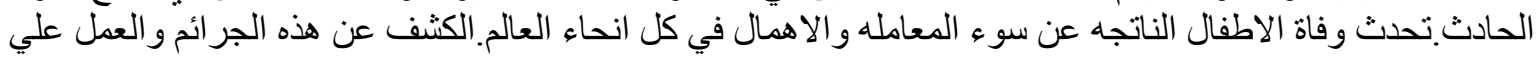
منعهاهو الاساس في كل الخدمات التي تحمي الطفل .

الهذف: هو وصف تو تر و نمط الوفيات غير الطبيعية فى مرحلتى الطفولة والمر اهقة فى القاهرة الكبرى خلال فترة سنة واحدة .

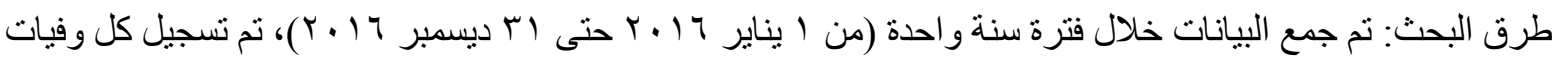

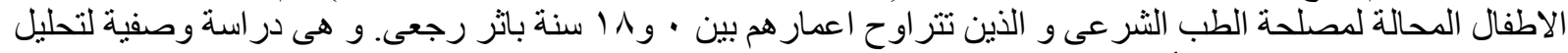

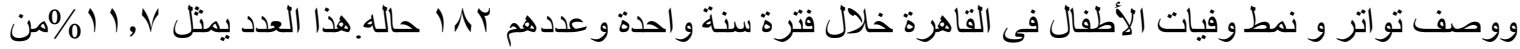

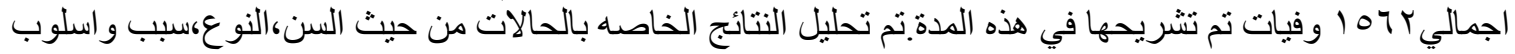

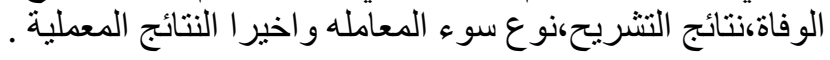
سرية البيانات :

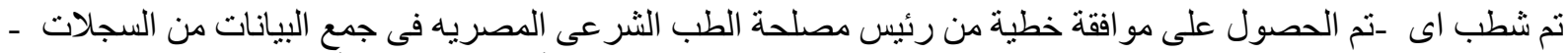

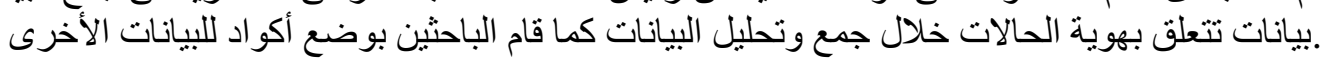

